\title{
Experimental study and Theoretical Simulations of Some Indolinone Based Mannich Bases as Novel Corrosion Inhibitors for Mild Steel in Acid Solutions
}

\author{
Chitrasen Gupta ${ }^{1}$ Ishtiaque Ahamad ${ }^{2}$, Ambrish Singh ${ }^{3,4, *}$, Xihua Xu ${ }^{4}$, Zhipeng Sun ${ }^{4}$ Yuanhua Lin ${ }^{3,4}$ \\ ${ }^{1}$ Department of Chemistry, Kutir Post Graduate College, Chakkey, Jaunpur, U.P., India. \\ ${ }^{2}$ Department of Applied Chemistry, Institute of Technology, Banaras Hindu University, Varanasi- \\ 221005, India. \\ ${ }^{3}$ State Key Laboratory of Oil and Gas Reservoir Geology and Exploitation, Southwest Petroleum \\ University, Chengdu 610500, China. \\ ${ }^{4}$ School of Materials Science and Engineering, Southwest Petroleum University, Xindu district- \\ 610500, Chengdu city, Sichuan province, China. \\ *E-mail: vishisingh4uall@gmail.com; drambrishsingh@gmail.com
}

doi: $10.20964 / 2017.07 .37$

Received: 5 April 2017 / Accepted: 4 May 2017 / Published: 12 June 2017

The adsorption behaviour of three Mannich bases [3-(4-chlorophenylimino)-1-(piperidin-1ylmethyl)indolin-2-one $\{\mathrm{M}-1\}, \quad 3$-(4-chlorophenylimino)-1-(morpholinomethyl)indolin-2-one $\{\mathrm{M}-2\}$ and 3-(4-chlorophenylimino)-1-[(dibutylamino)methyl]indolin-2-one $\{\mathrm{M}-3\}]$ on mild steel surface in $1 \mathrm{M} \mathrm{HCl}$ solution was investigated using electrochemical impedance spectroscopy (EIS), polarization curves, and weight loss techniques. The experimental results showed that all Mannich bases are good inhibitors showing $>90 \%$ inhibition efficiency. Potentiodynamic polarization measurements showed that all studied inhibitors are mixed type. Further, quantum chemical calculations were carried out and the relations between computed parameters and corrosion inhibition efficiency have been discussed.

Keywords: Electrochemical impedance spectroscopy; Mannich base; Corrosion; Quantum chemical calculations

\section{FULL TEXT}

(C) 2017 The Authors. Published by ESG (www.electrochemsci.org). This article is an open access article distributed under the terms and conditions of the Creative Commons Attribution license (http://creativecommons.org/licenses/by/4.0/). 